\title{
Concepto y proceso en Peter Eisenman y Sol LeWitt: la disolución de la forma
}

\author{
Rafael García Sánchez \\ Universidad Politécnica de Cartagena
}

RESUMEN:

En el seno de la pintura y la arquitectura, tuvo lugar a finales de 1960 el desarrollo del arte conceptual. Tal es el caso de una parte de las obras y escritos de LeWitt y Eisenman. Más allá de la corriente abstracta, el arte y la arquitectura conceptuales pretendían la objetividad. La vertiente conceptual no se centraba ni en la finalización del objeto ni en la forma misma, sino en el proceso. Lo conceptual guarda relación con los procedimientos más que con los objetos en sí. En este texto haciendo uso de las nociones de belleza y de juicio que llevara a cabo Kant en la Crítica del juicio, se hará notar que la experiencia de lo conceptual caería del lado de lo meramente intelectual frente a la presencia y experiencia de lo bello, completamente emancipada de finalidad o interés alguno.

\section{PALABRAS CLAVE:}

Conceptual, Abstracto, Kant, Belleza, Arquitectura.

\section{ABSTRACT:}

In the bosom of painting and architecture, the development of conceptual art took place at the end of 1960. Such is the case of a part of the works and writings of Eisenman and LeWitt. Apart from the abstract trend, conceptual art and architecture wanted the objectivity. The conceptual aspect was not centered neither in the finalization of the object nor in the form itself, rather in the process. The concept relates to the procedures rather than the objects themselves. In this text making use of the notions of beauty and judgment that will hold Kant in the Critique of judgment, is to be noted that experience of the conceptual would fall on the side of the purely intellectual in front of presence and experience of the beautiful, fully emancipated to the purpose any interest.

\section{KEY WORDS:}

Conceptual, Abstract, Kant, Beauty, Architecture. 


\section{Introducción}

El conceptual art es una de las manifestaciones artísticas del siglo XX que, desarrollado entre los años sesenta y los setenta, certificará lo que se ha definido como deslizamiento "de la estética hacia la filosofía del arte" ${ }^{1}$, "de la estética a la crítica de arte" 2 . Esta corriente hará énfasis en la falta de correspondencia entre objeto y concepto artístico. Llevará al extremo la cuestión por la exigencia del objeto, constatará la sustancial diferencia entre lo sabido y lo representado, y hará transitar el arte "del objeto a la idea" y "de una definición material a un sistema de pensamiento", dirá Morgan $^{3}$. En la misma línea insistirá Lippard, en tono biográfico, cuando dice: "Para mí, el arte conceptual significa una obra en la que la idea tiene suma importancia y la forma material es secundaria [...]"4.

Ciertamente se pueden detectar dos tendencias conceptuales, una lingüística y otra procesual. Su denominador común será el alejamiento de la importancia dada a la percepción y la experiencia visual y lo harán en línea de continuidad con la dimensión anti-retinal del arte defendida por Duchamp, para muchos de entonces "[...] la fuente más evidente en la historia del arte" primera vertiente conceptual otorgó una singular primordialidad al lenguaje y lo hizo prevalecer sobre el efecto visual de la representación. Acudirá a las proposiciones lingüísticas como fundamento explicativo de lo que subyace a la actividad artística. Al respecto, anotará Kosuth, "una obra de arte, es una especie de proposición [...]”6. La tendencia procesual, en cambio, llevará a cabo una nítida distinción entre el objeto y el proceso. De hecho, el objeto ya no estará presente como resultado final sino como mero registro de un proceso.

MARCHÁN FIZ, Simón, La estética en la cultura moderna, Alianza Forma, Madrid, 2007, pp. 225.

DANTO, Arthur. C., Después del fin del arte. El arte contemporáneo y el linde de la historia, Paidós, Barcelona, 1999, pp. 97-114.

3 MORGAN, Robert C, Del arte a la idea. Ensayos sobre arte conceptual, Akal, Madrid, 2003, pp. 12.

4 LIPPARD, Lucy R., Seis años: la desmaterialización del objeto artístico. De 1966 a 1972, Akal, Madrid, 2004, pp. 8.

5 LIPPARD, Lucy R., Seis años: la desmaterialización del objeto artístico. De 1966 a 1972, opus cit., pp. 10.

6 KOSUTH, Joseph, "Arte y Filosofía” en Simón Marchán Fiz, Del arte objetual al arte del concepto. Epílogo sobre la sensibilidad postmoderna, Akal, Madrid, 1994, pp. 415.
El arquitecto Peter Eisenman participará, entre 1968 y 1978, de la tendencia conceptual más analítica y lingüística; no en vano alude con frecuencia a la influencia que para él supuso el trabajo de Chomsky. Sin embargo, su proceder proyectual y arquitectónico, a nuestro modo de ver, acabará empujándole hacia la dimensión procesual y terminará por emparentarle, en la teoría y en la práctica, con Sol LeWitt, conceptualista marcadamente procesual. Tanto Eisenman como LeWitt, "liberados del status del objeto"7, harán prevalecer lo mental sobre lo perceptivo, y los aspectos profundos sobre los superficiales ${ }^{8}$. Ambos reducirán el objeto artístico, tal es el desplazamiento, entre otros motivos para salvarlo del mercado consumista. Otorgarán una singular jerarquía al proceso de producción y generación que corresponderá al entendimiento conocer. Neutralizarán el gusto y la experiencia visual, exigiendo del espectador un alto nivel y disposición cultural. En suma, estarán más preocupados por la intelección de las relaciones profundas y menos por la recepción sensitiva del objeto artístico.

A lo largo del texto se hará notar el sentido intelectual de lo conceptual -como lo propio de las actividades cognitivas y detectivescas que diría Stan Allen" - frente a la belleza que "pasando por encima del concepto" ${ }^{10}$, solo podría experimentarse ante lo completamente emancipado, esto es, ante lo abstracto, lo absoluto y lo que "no recibe ley alguna de otro"

Con el fin de vincular teoría y práctica, haremos referencia a los textos y a algunas de las obras que tanto Lewitt -iniciador del arte conceptual a partir de sus Sentencias ${ }^{12}$ - como Eisenman, realizarán en las décadas de los 60 y 70 del siglo XX. Constataremos la semejanza de algunos de los resultados finales de sus obras, la importancia del proceso frente a la forma o al objeto autoafirmado, incondicionado y autorreferenciado. Y concluiremos defendiendo

\footnotetext{
LIPPARD, Lucy R., Seis años: la desmaterialización del objeto artístico. De 1966 a 1972, opus cit., pp. 7.

8 MONEO, Rafael, Inquietud teórica y estrategia proyectual en la obra de ocho arquitectos contemporáneos, Actar, Barcelona, 2004, pp. 150.

9 DAVIDSON, Cynthia, Tras el rastro de Eisenman, Akal, Madrid, 2006, pp. 49.

10 KANT, Inmanuel, Crítica del juicio, Espasa, Madrid, 2014, §36, pp. 228

11 PAREYSON, Luigi, L'etetica de Kant. Lettura della “Critica del Giudizio", Mursia, Milano, 1984, pp. 89.

12 DIEGO, Estrella de, Artes visuales en Occidente, opus cit., pp. 62.
} 
que más que de una experiencia de lo bello se debería hablar del mero agrado o satisfacción intelectual, que terminará por convertir el proceso en fin. Tal es la sustancia didáctica de lo conceptual y tal es el deslizamiento producido desde la estética hacia la filosofía y la crítica del arte.

\section{Objeto, no-objeto, proceso}

Conviene revisar el calificativo "conceptual" cuyo significado se ha vuelto confuso. Lo haremos, como hiciera Greenberg, basándonos en la estética kantiana, no en vano considera a Kant el "primer moderno verdadero" ${ }^{13}$. Como es sabido, una parte del arte del siglo XX celebra su mayoría de edad, y participa de la noción de belleza desarrollada en la Crítica del juicio y cuya influencia, anota Gadamer, se ha hecho evidente a través de diferentes corrientes neokantianas en escritores de arte y estética ${ }^{14}$. Para Kant, las nociones de "belleza" y de "juicio de gusto estético puro”, también su carácter desinteresado y emancipado de finalidad, no hacen referencia a lo conceptual sino a la falta de ello pues: "[...] bello es lo que sin concepto es representado como objeto de una satisfacción universal" ${ }^{15}$, dado que "[...] el juicio de gusto no subsume nada bajo un concepto" ${ }^{16}$, y "[...] cuyo fundamento de determinación no puede ser concepto alguno" ${ }^{17}$. Por tanto, y siguiendo a Gadamer, el arte abstracto no sería propiamente un arte conceptual sino más bien un arte "no objetual" 18 o no figurativo, desarrollado como alternativa a las tres alienaciones del arte convencional: la naturaleza, la evocación y el entorno ${ }^{19}$.

¿Qué nos hace llamar bello a un objeto? Deberíamos responder con Kant que no sería la comprensión conceptual del contenido objetual, tampoco la representación del ideal de lo representado: "[...] bello es lo que sin concepto es representado como objeto de una

13 GREENBERG, Clement, La pintura moderna y otros ensayos, Siruela, Madrid, 2006, pp. 111.

14 GADAMER, Hans-Georg, Estética y hermenéutica, Tecnos, Madrid, 2001, pp. 85.

15 KANT, Inmanuel, Crítica del juicio, opus cit., §6, pp. 36.

16 KANT, Inmanuel, Crítica del juicio, opus cit., §35, pp. 225.

17 KANT, Inmanuel, Crítica del juicio, opus cit., §15, pp. 156.

18 GADAMER, Hans-Georg, Estética y hermenéutica, opus cit., pp. 88.

19 RUBERT DE VENTÓS, Xavier, El arte ensimismado, Anagrama, Barcelona, 1977, pp. 41. satisfacción universal”20. Bello sería lo que provoca en el espectador un tipo de satisfacción sin interés y sin concepto, y no la representación ideal del objeto ni la alusión a referencia externa, tampoco su eficacia emotiva ni su concordancia decorativa. Más aún, la belleza no es algo que pueda ser captado por el entendimiento sino a través del juicio de gusto y que para el filósofo de Königsberg se opone al conocimiento teórico pues: "los juicios de gusto [...] pasan por encima del concepto y hasta de la intuición del objeto, y añaden a esta [...] algo que ni siquiera es conocimiento, a saber, un sentimiento de placer (o dolor)" ${ }^{21}$. En resumen, desde la óptica kantiana, la experiencia de lo bello no estaría emparentada ni con el contenido ni con finalidad alguna ni con los conceptos ni con los procesos. Es desinteresada y no es algo en el objeto sino más bien en el sujeto.

Dicho esto, ¿cómo debemos entender el arte conceptual si todavía mantiene en pie la desintegración de la figura y la forma, el predominio de los valores no referenciales del color, la deconstrucción del sistema espacial, etc. tan definitorio del periodo abstracto? ${ }^{22}$. A diferencia del arte abstracto -que otorgaba primordialidad a la autonomía de la forma artística, y que perseguía "un tipo de experiencia valiosa por sí misma" 23 , el arte conceptual orilla la importancia del objeto o la forma en sí, desplazándola a favor del proceso de gestación de la obra: la autonomía pretendida se convirtió en "un concepto que participa de la metafísica misma a desplazar"24. Todo ello, indica Marchán Fiz, generó la corriente de desmitificación progresiva del objeto a favor del concepto ${ }^{25}$ que "no se percibe a través de los sentidos [...] sino a través de la mente"26, anota Eisenman. El concepto solo es comprensible mediante una actividad mental

\footnotetext{
KANT, Inmanuel, Crítica del juicio, opus cit., §6, pp. 136. 21 KANT, Inmanuel, Crítica del juicio, opus cit., §36, pp. 228. 22 MARCHÁN FIZ, Simón, La estética en la cultura moderna, opus cit., pp. 230.

23 GREENBERG, Clement, La pintura moderna $y$ otros ensayos, opus cit., pp. 112.

24 EISENMAN, Peter, "Misreading Peter Eisenman", en Eisenman Inside Out. Selected Writings 1963-1988, ed. Peter Eisenman, Yale University Press, New Haven and London, 2004, pp. 221.

25 MARCHÁN FIZ, Simón, Del arte objetual al arte de concepto, opus cit., pp. 250.

26 EISENMAN, Peter, "Del objeto a la relación [II]. La Casa Giuliani-Frigerio de Giuseppe Terragni”, en 11+L Una antología de ensayos, Puente Editores, Barcelona, 2017, pp.45.
} 
desvelado en el proceso de elaboración que se ha vuelto primordial frente al resultado final.

$\mathrm{Al}$ respecto, es revelador que la arquitectura conceptual de Eisenman haya sido tildada de "cardboard architecture" 27 dado que es a través de los múltiples avances y retrocesos revelados en las maquetas, donde el arquitecto muestra el proceso de gestación de la obra, esto es, su sustancia. Lo que percibimos del arte conceptual, anota Marchán Fiz haciendo ver una deuda kantiana no tan evidente, "no son fines formales en sí mismos, no son la obra, sino las señales, los documentos de otros fenómenos, que abren nuestra conciencia a algo exterior. [...] Como consecuencia, la ejecución tradicional es irrelevante en el marco de la transición del objeto a la estética como proceso" ${ }^{28}$. En el mismo sentido sentencia Davidson: “[...] Eisenman confía una y otra vez en el proceso como forma de liberar la arquitectura de su propio lenguaje e intereses tradicionales, es decir, de la presencia como manifestación de la verdad" 29 .

\section{De las ausencias y silencios a los procesos}

Entre la figura y el no-objeto media la primordialidad de la forma autorreferencial abstracta caracterizada por su falta de literalidad narrativa, desprovista de contenido semántico. A partir del siglo XIX, muchos autores investigaron sobre las ausencias y los silencios. Cézanne eliminó el discurso y la literatura de la pintura. El grupo francés Los incoherentes experimentó con el lienzo vacío en 1883. Malevich en Cuadrado blanco sobre fondo blanco continuó esta reflexión en 1918. John Cage, en el verano de 1952 con sus 4'33" investigó sobre los silencios y las ausencias. Rauschenberg en 1953 llevó al extremo el expresionismo abstracto mediante El borrado de un dibujo de Konning. Todos ellos, entre muchos otros, vinieron a proponer que en la imitación de la realidad acababa imponiéndose -a través de ella- la literatura, el discurso y el contenido. La forma quedó disociada del contenido, lo que favoreció que el arte y la arquitectura se

27 MONEO, Rafael, Inquietud teórica y estrategia proyectual, opus cit., pp. 153.

28 MARCHÁN FIZ, Simón, Del arte objetual al arte de concepto, opus cit., pp. 252.

29 DAVIDSON, Cynthia, Tras el rastro de Eisenman, opus cit., pp. 29. replegaran sobre sí "como si su discurso no pudiera tener como contenido más que decir su propia forma" ${ }^{30}$. Así pues, de las obras de arte y arquitectura presencial, donde la forma era manifestación de la verdad o de su función, se transitó hacia la ausencia y el vacío, y quedó el proceso como único mecanismo para manifestar la idea o el concepto. El arte, en el sentido tradicional, falleció dos veces: primero la forma se quedó sin contenido y después, la prevalencia estructuralista del proceso, devaluó la forma desplazándola. Marchán Fiz, lo ha anotado en los siguientes términos "[...] desde el arte conceptual, la poética se convierte en el núcleo de su programa hasta desplazar a la misma obra como objeto físico. Importan más los procesos formativos y artísticos de la constitución que la obra realizada. En ello se acusa la transición de la obra como objeto a la estética procesual y conceptual" ${ }^{31}$.

Con todo, el tránsito hacia el proceso puede intuirse en dos pequeños escritos que LeWitt y Eisenman realizaron entre 1968 y 1970. Participando de los silencios y las ausencias, expresaron la relevancia de la no referencialidad. Nos referimos a las treinta y cinco Sentences on Conceptual Art de LeWitt ${ }^{32} \mathrm{y}$ a las Notes on Conceptual Architecture de Eisenman ${ }^{33}$; nótese la similitud de ambos títulos. En ambos textos se pretende situar la experiencia artística más allá de la convencionalidad y transportabilidad de las formas, intelectualizando dicha experiencia mediante la racionalización y objetivación, esto es: mediante su conversión en conceptos. Es bien ilustrativa la Sentencia 8 de LeWitt, donde leemos que "Cuando se emplean palabras tales como pintura y escultura, connotan toda una tradición e implican una aceptación consiguiente con esa tradición, poniendo así limitaciones al artista" ${ }^{34}$. Probablemente, influido por ello, Peter Eisenman lleva a cabo un texto sin texto, un texto sin litera-

\footnotetext{
30 MARCHÁN FIZ, Simón, La estética en la cultura moderna, opus cit., pp. 230.

31 MARCHÁN FIZ, Simón, Del arte objetual al arte de concepto, opus cit., pp. 13.

32 MARCHÁN FIZ, Simón, Del arte objetual al arte de concepto, opus cit., pp. 414, 415.

33 EISENMAN, Peter, "Notas sobre arquitectura conceptual”, en $11+L$ Una antología de ensayos, en opus cit., pp.35-39.

34 MARCHÁN FIZ, Simón, Del arte objetual al arte de concepto, opus cit., pp. 414.
} 
tura en Notas sobre arquitectura conceptual ${ }^{35}$. Tan solo aparecen unas puntuaciones y unas referencias a pie de página, (Sol LeWitt aparece citado en la nota 3), señalando el ensimismamiento y emancipación absoluta respecto del discurso, el lenguaje y la narración, con el fin de evitar interferencias y limitaciones alienantes a su comprensión. Con ese texto abierto - tal y como reseñase Lewitt explícitamente en la Sentencia 8 - pone de relieve que un tipo de arte del concepto, y no del texto o de la forma, no recibiría interferencias de tradiciones, costumbres y lenguajes que limitasen la creación y la experiencia artística. Sin embargo, más que de no-referencialidad y de emancipación de limitaciones, la singularidad de LeWitt y de Eisenman, consiste en que su proceder no está orientado a la producción de un artefacto final formalmente puro, sino a la explicitación del proceso. La idea, el concepto y el proceso son propiamente el cometido del $\operatorname{artista}^{36}$. Su producción puede quedar en manos externas de técnicos y operarios que solo han de seguir el proceso marcado y descrito por el autor, como si de una guía o manual de montaje se tratase. Al espectador le queda como labor descubrir -en el sentido detectivesco del término- las huellas de un suceso, en suma: las pistas expresadas por el artista en el proceso.

Las obras de LeWitt, fruto de operaciones complejas y procesos numérico-geométricos pueden ser realizadas por otros. Tal es el caso de los dibujos de pared: ni el espacio es determinante, ni el artista es necesariamente el productor. La distancia entre proceso y realización radicaliza su carácter conceptual, basta la idea y el proceso. En arquitectura sucede otro tanto. El arquitecto no es el constructor, solo quien tiene la idea cuya generación se expresa en el proyecto ejecutado por un segundo actor. El proyecto revelaría las estructuras profundas cuyas leyes gobiernan el desarrollo de la obra. El proceso de gesta-

35 EISENMAN, Peter, "Notas sobre arquitectura conceptual”, en 11+L Una antología de ensayos, en opus cit., pp.35.

36 Para artistas conceptuales como Douglas Huebler y D. Dye, también para LeWitt, entre otros, lo importante de la obra de arte ya se ha producido antes de su ejecución. Les basta con indicar verbalmente que parámetros han de seguir los instaladores para hacer materializar la idea. Al respecto, anotaba Joseph Beuys en 1969: “[...] Para mí la formación de la idea ya es cultura”, en Lucy R. Lippard, Seis años: la desmaterialización del objeto artístico. De 1966 a 1972, opus cit., pp. 21. ción, las estructuras inconscientes, sus leyes, prevalecen sobre el objeto. Si, pongamos por caso, observamos un tablero de ajedrez con sus piezas, más revelador que su disposición final es el análisis del conjunto de movimientos previos que han dado lugar a la situación final. Las piezas solo son el resultado final, en cambio, el proceso explica cómo han llegado a estar donde están, lo cual sería mucho más relevante para una comprensión de qué es jugar al ajedrez.

LeWitt insistirá en la prevalencia del proceso en la séptima de sus Sentences: "La voluntad del artista es secundaria respecto al proceso que él mismo pone en marcha desde la idea hasta la terminación. Su voluntariedad puede ser solo vanidad". En la 27 también hace referencia al proceso, no en vano afirma: "El concepto de una obra de arte puede tener que ver con la materia de una pieza o con su proceso de ejecución”. Eisenman participa de la procesualización del arte, y "centrará todo su esfuerzo como teórico de la arquitectura [...] a encontrar las estructuras, las leyes o principios que expliquen la aparición de la forma" ${ }^{37}$. No atenderá ni a la semantización ni a la formalización arquitectónica sino al proceso, a la estructura profunda que dirían Chomsky o Lévi-Strauss desplazando la estructura superficial, haciendo prevalecer la conceptual o profunda ${ }^{38}$. Por ello, anota Montaner: "para el autor, el modo de hacer se ha convertido en más importante que el artefacto [...]"39. De manera que lo representado ni es propiamente una idea ni es propiamente una figura o una forma. Lo que aparece es solo un proceso. El proceso prevalece sobre el resultado. La forma, su disposición, su geometría, su medida, etc. serían expresión de aquel, quedando alienadas, perdiendo el carácter absoluto y abstracto defendido, entre otras, desde la estética kantiana. En definitiva, indica Montaner: "Se trata de desplazar la atención desde la obra de arte como proceso acabado hacia el énfasis en el proceso de creación" ${ }^{40}$.

\footnotetext{
37 MONEO, Rafael, Inquietud teórica y estrategia proyectual, opus cit., pp. 148.

38 MONEO, Rafael, Inquietud teórica y estrategia proyectual, opus cit., pp. 150.

39 MONTANER, Josep $\mathrm{M}^{\mathrm{a}}$, Después del movimiento moderno. Arquitectura de la segunda mitad del siglo XX. Gustavo Gili, Barcelona, 1993, pp. 168.

40 MONTANER, Josep $\mathrm{M}^{\mathrm{a}}$, Después del movimiento moderno, opus cit., pp. 168.
} 


\section{Paralelismos formales}

Más allá de la semejanza entre las Sentencias de LeWitt y las Notas de Eisenman, queremos reseñar los paralelismos formales entre los resultados finales de algunas de sus obras donde se ha utilizado el cubo como "esencialidad primaria"41, para acabar otorgando mayor importancia al concepto (estructura profunda de relaciones) que al objeto (estructura superficial). La afinidad se origina al fundar el objeto artístico sobre la noción de proceso ("método transformacional") y que ambos articulan alrededor de retículas, mallas geométrico-numéricas, y una dimensión topológica del espacio. Eisenman, a propósito de la Giuliani-Frigerio, y LeWitt, en las Sentencias 7, 27 y 29 afirman que

"Uno de los aspectos del método transformacional, [...], trata de desplazar la respuesta primaria a la forma desde una naturaleza perceptiva hasta una conceptual: del objeto a la relación" ${ }^{42}$. "La voluntad del artista es secundaria con respecto al proceso que él mismo pone en marcha desde la idea hasta la terminación [...]". "El concepto de una obra de arte puede tener que ver con la materia de la pieza o con su proceso de ejecución". "El proceso es mecánico y no se debe interferir en él. Debe seguir su curso"43.

Ambos trabajan sobre el espacio abstracto cartesiano. La retícula, generadora del espacio neutro, es utilizada como dato y condición de partida. Esta es la base de la neutralidad y de la posibilidad de abstracción. Sobre la retícula se opera por acumulación, superposición, traslación y rotación; en ella se realizan desplazamientos, recortes y extracciones, concavidades y convexidades. Estas operaciones van dejando su rastro, su huella, su biografía generativa, que han de ser visibles y reconocibles. Toda obra conceptual debe registrar su biografía haciendo visible desde su origen las fases intermedias, la trayectoria, incluso sus rectificaciones.

${ }^{41}$ MARCHÁM FIZ, Simón, La historia del cubo: Minimal Art y fenomenología (cat.), Sala de Exposiciones Rekalde, Bilbao, 1993, pp.31.

42 EISENMAN, Peter, "Del objeto a la relación [II]. La Casa Giuliani-Frigerio de Giuseppe Terragni”, en $11+L$ Una antología de ensayos, en opus cit., pp.49.

43 MARCHÁN FIZ, Simón, Del arte objetual al arte de concepto, opus cit., pp. 414-415.
Insistamos: dado que no se produce un objeto sino la muestra de un proceso, no es relevante su estado definitivo o su resultado final sino el conjunto de operaciones previas (estructura profunda) que se han producido en su generación y que van a determinar la forma como estructuras inconscientes (freudianas, marxistas, lacanianas o straussianas). Por eso, Eisenman refiere que "[...] en arquitectura, una estructura profunda es aquella capaz de proporcionar una estructura de referencia, de modo que el significado pueda derivarse de una relación específica entre unas formas concretas" 44 .

Paralelismos los hay en los textos y en los resultados formales de algunas de sus obras. Los proyectos de vivienda que Eisenman realiza entre 1968 y 1978 -desde la House I en Princeton, para un coleccionista de juguetes, a la House XI en Palo Alto, para el historiador Kurt Forsterson bien ilustrativos del sentido de lo conceptual. Esta etapa sintáctica se nutre del estructuralismo de Chomsky, analista del lenguaje, de cuyos estudios pueden extraerse al menos dos ideas, anota Eisenman: 1. Que es posible separar la semántica de la sintaxis y 2. Que esta (la sintaxis), a su vez, posee dos niveles: uno superficial y otro profundo ${ }^{45}$. No obstante, a nuestro juicio, acaba deslizándose hacia un conceptualismo muy procesual, que desarrollará a través de una noción de espacio más topológico que euclidiano, a través de retículas y diagramas. Los resultados eisenmanianos son semejantes -basta con una mirada atenta a los diagramas compositivos de las casas- con algunas obras de LeWitt, como el Modular cube de 1967 y el 8 Part Cube de 1975, entre otros.

Nótese la importancia de la malla en la House I (1968). Descompone el cubo, aunque siempre lo mantiene reconocible. La malla está presente; no es simplemente un fondo neutro donde se colocan elementos. Esta se desplaza ortogonalmente generando intersecciones y superimposiciones. La malla activa es la generadora del proceso. En la House II en Hardwick, Vermont (1970), la actividad de la malla con base en el cuadrado se hace más notable y más intensa. Los desplazamientos ya no son ortogonales sino diagonales. Estos desplazamientos

${ }^{44}$ EISENMAN, Peter, "Del objeto a la relación [II]. La Casa Giuliani-Frigerio de Giuseppe Terragni”, en 11+L Una antología de ensayos, en opus cit., pp.43.

45 EISENMAN, Peter, 11+L Una antología de ensayos, opus cit., pp.47-48. 
activan el proceso poniendo de relieve que la arquitectura está más propiamente en él que en la forma final. Ni le importa el resultado ni la adecuación a la función ni la noción de forma pura. Para Moneo es la más interesante de toda la serie de casas del periodo conceptual pues hace muy evidente que la arquitectura se ha convertido en un objeto cuya forma no es caprichosa dado que ha recogido todas las operaciones geométricas de que da cuenta el proceso $^{46}$. En la House III en Lakeville (1971), la actividad de la malla ya no es traslacional ni ortogonal ni diagonal, sino rotativa. La malla cúbica gira apareciendo las primeras maclas no ortogonales. En 1971 lleva a cabo la House IV en Fall Village, que no se llega a materializar, no obstante, en el proyecto aflora "una máquina conceptual capaz de generar arquitectura por sí misma [...]"47. Con todo, sus diagramas compositivos y axonométricos revelan que "en el proceso no se tuvo en consideración si el resultado era arquitectura [...] el problema no fue diseñar un objeto, sino buscar y establecer un programa transformacional libre de las constantes autoriales tradicionales" ${ }^{48}$. Su interés recae, no tanto en la actividad de la malla, en sus desplazamientos, superimposiciones, maclas y giros, sino en la potencia del núcleo que al explotar desplaza los cuadrantes extremos. Este interés por el núcleo cúbico se hará visible de manera más intensa en la House VI en Cornwa11 (1975) donde las fronteras del cubo pierden densidad geométrica. El núcleo se ha convertido en el desencadenante del proceso de gestación del proyecto, devaluándose el valor del cubo. Con todo, "para Eisenman -anota Colin Davies- la casa VI ni siquiera es realmente un objeto, en el sentido final de un proceso. Más bien es un registro de un proceso" 49 .

Los diagramas compositivos de las casas $I V$ y $V I$ ofrecen una relación de afinidad con la obra 8 Part Cube (1975), con el Cube Structure Based On Five Modules (1972) el Untitled (Cube) (1979), también con la obra 12345 de 1979. Finalmente, la House $11 a$ en Palo Alto,

\footnotetext{
46 MONEO, Rafael, Inquietud teórica y estrategia proyectual, opus cit., pp. 158.

47 LORENZO-EIROA, Pablo, Instalaciones: sobre el trabajo de Eisenman. DLO/Robles Ediciones, Buenos Aires, 2008, pp. 25.

48 DAVIDSON, Cynthia, Tras el rastro de Eisenman, opus cit. pp. 44.

49 DAVIES, Colin, Casas paradigmáticas del siglo XX, Gustavo Gili, Barcelona, 2007, pp. 160.
}

California (1978), que tampoco se llegó a materializar, es considerada como la síntesis de toda la investigación de este periodo conceptual. El núcleo desplaza una esquina volumétrica del cubo generando concavidades y convexidades que dan lugar a la tensión dentro/fuera y lleno/ vacío, dicotomías dialécticas que ya no abandonará Eisenman en su etapa posterior, donde cambiará el punto de Arquímedes del estructuralismo procesual por otro metafórico y post-estructuralista, basado en Derrida y Deleuze. Este periodo, caracterizado por la confrontación con la logocentrista (Derrida) triada vitruviana y con la noción de borde o límite, inaugurará la etapa deconstructivista más centrada en los pliegues (Deleuze) y en los intersticios, generando las nociones de anti-firmitas (des-estructuración), anti-utilitas (des-funcionalización) y anti-venustas (des-familiarización).

La tensión del núcleo, que en la House 11a segrega la esquina cúbica, es igualmente apreciable en las pinturas de pared que LeWitt ideará en 1985, Wall Drawing 1171, y en 1969 donde "la obra no es sólo el objeto, sino el conocimiento de todo el proceso" 50 . También en el Cube without a cub en 1996 donde las similitudes formales entre las esculturas y dibujos de LeWitt y la arquitectura eisenmaniana son más que evidentes.

Por último, queremos reseñar, ya completamente fuera del periodo conceptual, las singulares afinidades formales de la obra que Eisenman proyectará para el Monumento al Holocausto de los judios de Europa en Berlín (1998-2005) con la obra Modelo para 46 variaciones de tres diferentes tipos de cubos que LeWitt desarrollará en 1968. A decir de Lorenzo-Eiroa, el Memorial de Berlín "tiene valor de, simplemente ser, en un estado de puro presente, y de ser la petrificación de ese estado (...)" ${ }^{51}$. No obstante, la disposición de los monolitos de hormigón, distribuidos en una retícula sin principio ni fin -en cuya contemplación y paseo solo cabe el silencio de la nada junto a la lectura no interpretativa a que da lugar el no-signogenera una forma final análoga a la obra que LeWitt llevará a cabo en 1968. Al respecto, es bien revelador, que Manfredo Tafuri incorpora-

\footnotetext{
50 MARCHÁN FIZ, Simón, Del arte objetual al arte de concepto, opus cit., pp. 262.

51 LORENZO-EIROA, Pablo, Instalaciones: sobre el trabajo de Eisenman, opus cit., pp. 100.
} 
ra en Five architects $N . Y^{52}$, la obra de Lewitt y que este realizara una nueva interpretación en 2005 de aquellas variaciones del 68 en la obra 6 variaciones de cubo. Estas y aquellas mantienen inevitables analogías formales y visuales entre sí.

\section{El juicio conceptual no es un juicio estético}

Montaner sostiene que la obra conceptual "se convierte en un proceso intelectual, y en ella predomina la idea por encima del objeto físico final" ${ }^{23}$ y que Eisenman realiza un tipo de arquitectura cuyo "placer" es alcanzado si se racionaliza la obra de arte y se traduce a conceptos $^{54}$, no en vano, Eisenman defiende la conceptualización no perceptiva de la experiencia arquitectónica ${ }^{55}$. Estas expresiones revelan el abandono de la noción de belleza kantiana pues el placer estético es bien distinto a la satisfacción que provoca el conocimiento intelectual o el saber mediado por conceptos. Mientras que el placer por la pura forma, sin mediación de concepto ni finalidad alguna, estaría vinculado al juicio estético puro, la satisfacción intelectual estaría vinculada a los juicios propiamente lógicos. Ni la racionalización sintáctica de la obra de arte ni su traducción a conceptos podría provocar un sentimiento de placer sino de satisfacción intelectual. Por otra parte, eso es lo que se pretende con el arte y la arquitectura conceptuales, y eso es lo que buscan Eisenman y LeWitt: hacer disponible, mediante la representación de la estructura profunda, un nivel de información objetiva que recaiga del lado del entendimiento que lo descubre y no de la experimentación sensible, de modo que su sustancia no es tanto fruitiva como "didáctica" ${ }^{56}$, dirá Moneo.

Ciertamente, aquí no se pone en duda que el saber y el conocer, propios de los juicios conceptuales, puedan generar un cierto tipo de sa-

52 TAFURI, Manfredo, Five architects N.Y. Officina Edizioni, Roma, 1981, pp. 14.

53 MONTANER, Josep $\mathrm{M}^{\mathrm{a}}$, Las formas del siglo XX, Gustavo Gili, Barcelona, 2002, pp. 78 .

54 MONTANER, Josep $\mathrm{M}^{\mathrm{a}}$, Después del movimiento moderno, opus cit., pp. 168.

55 EISENMAN, Peter, "Toward an Understanding of Form in Architecture", en Eisenman Inside Out. Selected Writings 1963-1988, opus cit. pp. 9.

56 MONEO, Rafael, Inquietud teórica y estrategia proyectual, opus cit., pp. 152. tisfacción. Lo que se pone en cuestión es que sea satisfacción estética. Para que sea de este tipo hace falta que no se decante ni subsuma en concepto alguno. El juicio estético no guardaría relación con el conocimiento ni con el saber, tanto da si hay proceso y registro, sino más bien con la pura forma, emancipada de finalidad alguna, tal es su desinterés. En el juicio estético puro no se conoce nada, solo se siente un placer que el objeto, por su pura formalidad, produce en el espectador.

De manera que, siendo rigurosos, al referirnos al arte y la arquitectura conceptuales no deberíamos esperar la experimentación del placer de lo bello sino más bien la satisfacción intelectual del conocimiento conceptual que el artista expresa procesualmente. Tal es la novedad que, como ha hecho notar Estrella de Diego, recae sobre todo del lado del espectador quien ante el happening, el arte inconsciente $\mathrm{y}$, a nuestro juicio también ante el conceptual art y la conceptual architecture, se coloca ante ellas de un modo inédito hasta entonces, excepción hecha de las experiencias dadá y futuristas de primeros del siglo $X^{57}$. Esta diferenciación entre lo que experimentamos de los objetos y lo que comprendemos de los procesos expresa el deslizamiento de la estética y la preocupación por lo bello, a la filosofía del arte y la preocupación por el arte como objeto de conocimiento. La estética queda orientada, "a una reflexión especulativa sobre los fenómenos de la belleza y del gusto, y la ciencia general del arte, preocupada por justificarlo y explicarlo en todas sus manifestaciones pasadas y presentes" ${ }^{58}$.

\section{La primordialidad del proceso: le fait de la structure est premier}

Como ya se ha insistido, el arte y la arquitectura conceptuales otorgan mayor relevancia al proceso de ideación y de composición que al resultado final: la sintaxis prevalece sobre la semántica y la biografía sobre el fin. Mediante el arte o la arquitectura del proceso se rechaza la idea de que el proceder artístico deba destinarse a la materialización concreta de una obra ya que su sustancia es didáctica. Al respecto,

\footnotetext{
57 DIEGO, Estrella de, Artes visuales en Occidente, opus cit., pp. 25.

58 MARCHÁN FIZ, Simón, La estética en la cultura moderna, opus cit. pp. 232.
} 
son reveladoras las palabras de Kosuth: "La mejor obra, en nuestro tiempo, es aquella que muestra el proceso del arte. Tal obra incluye al espectador como parte de la conversación, incorporándolo al proceso cultural e histórico del artista que la ha producido. Los artistas entienden el arte como un proceso" 59 .

Aunque el arte abstracto participe, entre otras, de la estética kantiana, el arte conceptual con su prevalencia estructural se emancipa de dicha jurisdicción, dado que la forma final es irrelevante. Hacer visible los factores que comparecen y "preformatean" la gestación de la obra es más determinante que el objeto en sí. No tiene sentido la prevalencia de la forma pura para una experiencia estética pura porque ese no es el fin. Tampoco tiene sentido, al menos en el caso de la arquitectura, la adecuación a una finalidad, volvamos a insistir, pues prevalece el proceso y no la forma subordinada que transformaría la arquitectura en "vulgar funcionalismo" ${ }^{60}$. De hecho, como defiende Eisenman, una de las razones que hicieron que la arquitectura moderna no alcanzara su plenitud fue el compromiso adquirido con el funcionalismo ${ }^{61}$. A la pregunta por el papel que desempeña la función en el proyecto arquitectónico, responde letalmente para el sentido clásico y tradicional de la disciplina:

“¿Qué es la función? Cuando se analiza un edificio, ¿a quién le importa si funciona bien como museo o no, cuál es su uso? Cuando contemplo las villas palladianas, no me importa en absoluto para qué usos se proyectaron, yo miro a la arquitectura. Todos los edificios funcionan, y como todos los edificios no son arquitectura, la función no debe tener nada que ver con la arquitectura" ${ }^{62}$.

Entones, cabe preguntarse si es posible la experiencia estética, dado que el proceso no produce el placer de lo bello. Primero porque el objeto ya no es propiamente el fin ni el re-

KOSUTH, Joseph, “Sobre el arte conceptual”, en Revista de Occidente, 165, Madrid, 1995, pp. 62-63.

60 FRAMPTON, Kenneth, Historia crítica de la arquitectura moderna. Gustavo Gili, Barcelona, 1991, pp. 303.

61 MONEO, Rafael, Inquietud teórica y estrategia proyectual, opus cit., pp. 147-148.

62 EISENMAN, Peter, "Entrevista realizada por Fuensanta Nieto y Enrique Sobejano" en Arquitectura. Revista del colegio oficial de arquitectos de Madrid, 270, Madrid, 1988, pp. 129. sultado final, es solo el proceso, como ya se vislumbraba en el expresionismo abstracto y que derivaría en el process art. Y segundo, porque su misión es didáctica y sintáctica, ni representativa ni semántica. Ciertamente, en el proceso pueden diluirse los conceptos de lo que las cosas son, pues solo aparecen representados los trámites y condicionantes intermedios entre la concepción y el alumbramiento ¿Eso querría decir, como apunta Montaner, que la arquitectura conceptual no debe tener significado y que debe olvidarse de su pretensión pragmática? En términos kantianos habría que responder no, porque ni la ausencia de significado ni la ausencia de finalidad podrían generar el sentimiento de lo bello, pues quedaría el proceso o sus mecanismos internos ${ }^{63}$ que no son propiamente ausencia de fin, sino más bien su finalidad más evidente, por lo que el objeto no se podría percibir desinteresadamente. Lo que al espectador le correspondería no es el juicio estético puro sino el desvelamiento comprensivo y hermenéutico del proceso de gestación de la obra que es, en sentido estricto, su finalidad. Las diferencias arquitectónicas obedecerían a diferencias de procesos o de mecanismos de composición pero no a diferencias propiamente formales ni figurativas ni funcionales. Así, la forma o la figura que aparece en las esculturas y en algunas arquitecturas conceptuales no son solo el decantado final de un proceso sino, más bien, el proceso mismo que se ha vuelto mundo y por eso se hace visible.

\section{Conclusiones: el proceso como fin y como forma}

Los escritos de LeWitt y de Eisenman, sus esculturas reticuladas, sus análisis cúbicos, los desplazamientos, superimposiciones y rotaciones sólo pueden abordarse comprensivamente desde la primacía del concepto y del proceso, y pretenden destacar que la obra de arte y de arquitectura conceptuales son ajenas a la forma, al uso y a la finalidad. De la primacía de la forma se transita a la primacía del proceso y de la estética a la filosofía del arte. El objeto en sí ha perdido interés. El sujeto ahora tiene como cometido desenmascarar la estructura profunda del hecho artístico.

\footnotetext{
63 MONTANER, Josep $\mathrm{M}^{\mathrm{a}}$, Las formas del siglo $X X$, opus cit., pp. 78.
} 
Tal y como se ha indicado, el arte conceptual carece de pretensión semántica y pragmática, solo tiene sintáctica. Y como ha advertido Marchán Fiz, el arte y la arquitectura conceptuales de LeWitt y Eisenman se han centrado en la sintaxis, es decir, en el hallazgo y desenmascaramiento de las estructuras que legislan el ordenamiento de los elementos de la forma artística y arquitectónica. Tal es la labor detectivesca a la que queda sujeto el espectador y el crítico, quienes, más que disfrutar de lo bello, pretenden comprender, encontrar las pistas para reconstruir el sentido del suceso. Así es como se ha operado, ya se ha dicho, "la transición de la estética de la obra a la estética procesual y conceptual" y el deslizamiento "de la estética a la crítica de arte". No obstante, es un arma de doble filo, pues a decir de Morgan, el arte conceptual "ha resultado innecesariamente opaco, contribuyendo con ello a una genuina falta de crítica, como si el arte de las ideas pudiera existir, en cierto modo, libre de toda clase de criterios cualitativos" ${ }^{64}$. Más aún, al desproveer a la obra de arte y de arquitectura de un resultado final, de forma absoluta y de adecuación a fin, la contemplación pura, incluso el uso, se vuelven insustanciales. La disolución de la forma y del fin en la afirmación estructural y sintáctica del proceso ha terminado por subordinar las dimensiones semánticas y pragmáticas del arte y la arquitectura al primado del concepto. Este se expresaría en el proceso de creación, en los mecanismos de composición, pero nunca en una forma final pura que se ha vuelto irrelevante como forma.

Se ha advertido que el observador alcanzaría "el placer de disfrutar de la obra de arte si ésta es racionalizada, traducida a conceptos" 65 . En términos kantianos y greenbergianos, este planteamiento conceptual-no-objetual, que

\footnotetext{
64 MORGAN, Robert C, Del arte a la idea. Ensayos sobre arte conceptual, opus cit., pp. 13.

65 MONTANER, Josep $\mathrm{M}^{\mathrm{a}}$, Después del movimiento moderno, opus cit., pp. 168.
}

concede primacía a lo procesual y no a lo formal ni a lo semántico ni a lo pragmático, ha abandonado la noción del placer estético y de belleza. Sin embargo, el fin y el resultado siguen vigentes, aunque ahora no son forma pura sino proceso conceptual, cuyo interpretación y reconstrucción queda encomendada al observador. Y puesto que el placer de lo bello es un placer desinteresado -es finalidad sin fin, no subsume bajo conceptos y está vinculada a la forma - tanto la obra de arte como de arquitectura conceptuales no podrían provocar semejante placer, sólo el agrado o satisfacción del conocimiento de un proceso o de un mecanismo que se ha "respetado estrictamente" 66 y que se han vuelto fin. Tal es su sentido didáctico y su interés, y tal es el nuevo papel del observador: el del detective que reconstruye toda la historia de gestación de un suceso del que cabe sospechar que tiene por origen un cierto grado de arbitrariedad artística, diría Moneo. Vienen al caso, las palabras de Dashiell Hammet:

“(..) nos consagramos a estudiar los detalles, a la laboriosa tarea de seguirle la pista al asesino. Siempre hay una pista que va del crimen al autor. Es posible que como en esto, sea confusa. Sin embargo, como la materia no se mueve sin perturbar otra materia que encuentran en su camino, siempre existe tiene que existir- algún tipo de pista. Hallar y seguir dichas pistas es la razón por la que los detectives cobran sus honorarios" ${ }^{67}$.

Con todo, la pretendida objetividad conceptual no es del todo posible porque somos sujetos históricos ${ }^{68}$, porque los hechos y las pistas siempre se hallan insertas en la Historia, porque la exégesis procesual o reducción del arte a su "grado cero" es inevitablemente epocal. 